\title{
Commentary: Do the right thing! Ethical versus legal
}

\author{
W. Randolph Chitwood, Jr, MD
}

\author{
From the East Carolina Heart Institute and Department of Cardiovascular Sciences, Brody School of Medicine, \\ East Carolina University, Greenville, NC. \\ Disclosures: Author has nothing to disclose with regard to commercial support. \\ Received for publication Nov 14, 2018; accepted for publication Nov 15, 2018; available ahead of print Dec 28, \\ 2018. \\ Address for reprints: W. Randolph Chitwood, Jr, MD, 146 East Longmeadow Rd, Greenville, NC (E-mail: \\ Chitwoodw@ecu.edu). \\ J Thorac Cardiovasc Surg 2019;157:1941-2 \\ $0022-5223 / \$ 36.00$ \\ Copyright (C) 2018 by The American Association for Thoracic Surgery \\ https://doi.org/10.1016/j.jtcvs.2018.11.057
}

I heard an inspiring talk by Coach Lou Holtz at a recent surgical meeting. One of his 3 life rules was to "Do the right thing!" The article by Woo and colleagues ${ }^{1}$ debates this point in spades. Why are we so lucky to be the ones to help a patient through complex surgery? It is because we are trained, experienced, and engaged in changing people's lives. We are a profession, not just professional! Many new technologies have foisted surgeons into the conundrum- "Should I embrace new technology in surgical care or stick to proven methods with good outcomes?"

Mitral valve surgery is complex in and of itself. In this article, Woo and colleagues cited publications that showed that mitral repair results and complications are dependent on both center and surgeon referral volume as well as experience. Robot-assisted mitral valve surgery requires not only surgeon expertise but also a leading a synchronous heart team to deploy a complex, electromechanical device. Recently, we published suggestions as to the proper training paradigm for developing a robotic cardiac surgical program. ${ }^{2}$ Albeit, these were not firm guidelines, but there was a strong emphasis on specific entry criteria as well as stepwise training and proctoring essentials for a successful program.

When discussing an upcoming robot-assisted operation, more than legal informed consent is necessary. Dr Handy called understanding as 1 of the 7 components of informed consent. I like to call it "informed understanding." This requires that the patient understand everything about the surgeon's experience, his/her outcomes, alternate therapies, risks, and benefits. Woo and colleagues showed that in some court cases the opinion was that the surgeon is not legally bound to disclose his/her experience. Moreover, Handy opined that disclosure obligation exists only if asked by the patient. He wanted to protect the patient from added emotional stress. The arguments of both Woo and Handy

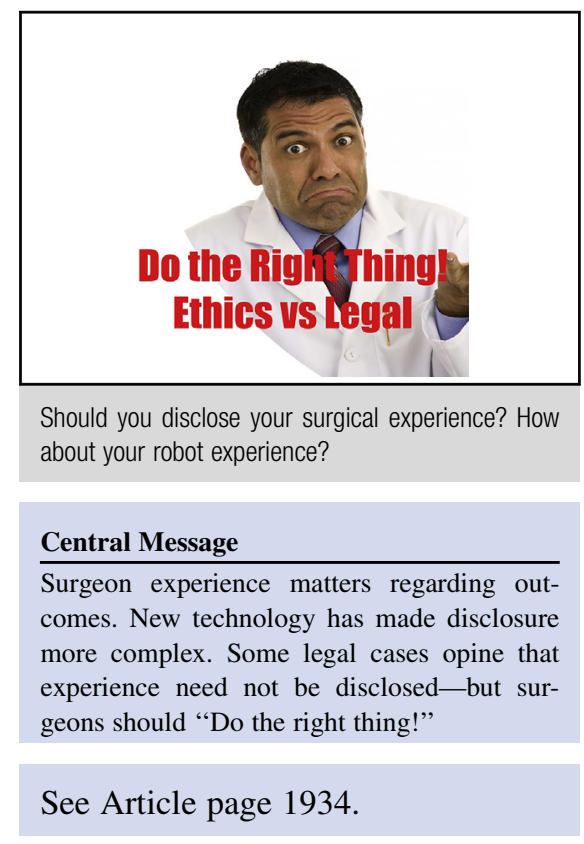

are cogent, but we as surgeons must decide which route to choose.

As one who has been involved in both minimally invasive and robot-assisted mitral surgery since the mid-1990s, the conundrum presented in this debate arose many times. My insight as to what should be disclosed to Mr Chamberlain differs from Dr Handy's opinion. Dr Asimov seems well qualified by some standards, and he had success with a single robotic operation. He took all the steps to have de facto "positive evaluations" from the robot company. He has seen several robotic mitral operations at an experienced center; nevertheless, he does not have plans to have a proctor during Mr Chamberlain's operation.

The premise of the debate did not reveal his mitral repair experience or whether he had done any minimally invasive operations. Experience with both of these seems necessary before advancing to the complexities of robot-assisted mitral surgery. I can only cite my personal experience, having performed both the first videoscopic minimally invasive and da Vinci robotic mitral repairs in the United States in 1996 and 2000, respectively. I disclosed to these patients that they were to be the "first." They were very anxious until I explained my mitral repair experience, how I would manage complications, and that early conversion to a sternotomy was possible. To this surgeon, it does not matter what are the legal ramifications of full disclosure. A good-hearted surgeon can allay most patient anxieties. So, in my opinion, just "Do the right thing!" 


\section{References}

1. Woo JYT, Handy JR Jr, Sade RM. First in line for robotic surgery: would you want to know? J Thorac Cardiovasc Surg. 2019;157:1934-40.
2. Rodriguez E, Nifong LW, Bonatti J, Cassula R, Falk V, Folliguet TA, et al. Pathway for surgeons and programs to establish and maintain a successful robot-assisted adult cardiac surgery program. J Thorac Cardiovasc Surg. 2016;152:9-13. 